\title{
Magnitude and Associated Risk Factors of Superficial Skin Fungal Infection Among Primary School Children in Southern Tanzania
}

\author{
Rahel Chikoi ${ }^{1}$, Helmut A. Nyawale ${ }^{2}$, Fabian P. Mghanga ${ }^{3}$ \\ 1. Department of Community Medicine, Archbishop James University College, Songea, TZA 2. \\ Department of Microbiology and Immunology, Archbishop James University College, Songea, TZA 3. \\ Department of Internal Medicine, Archbishop James University College, Songea, TZA
}

$\square$ Corresponding author: Rahel Chikoi, rahel.chikoi@gmail.com

Disclosures can be found in Additional Information at the end of the article

\section{Abstract}

Introduction: Superficial skin fungal infections are among the neglected communicable diseases in many developing countries. Schoolchildren are among the most affected groups in Southern Tanzania. The main objective of this study was to determine the magnitude and associated risk factors of superficial skin fungal infections among primary schoolchildren in Southern Tanzania.

Methods: A cross-sectional descriptive community-based study was conducted in October 2017 in a public primary school in Songea Municipal, Southern Tanzania. A sample of 500 pupils was interviewed and a physical examination performed to assess for the presence of clinically suspected skin fungal infections. Data were analyzed by SPSS v21 (IBM Corp., Armonk, NY, US).

Results: A total of 500 pupils (52.40\% males) with a mean age of $9.92 \pm 1.13$ years were recruited. The point-prevalence of skin fungal infections was $35.20 \%$. Tinea capitis was the leading suspected skin fungal disease found in 73 (80.22\%) pupils. Age between 10 and 12 years and sharing of a bed with more than three people were significantly associated with the development of superficial skin fungal infections $(\mathrm{p}<0.05)$.

Conclusion: Our findings indicate that the magnitude of superficial skin fungal infections among schoolgoing children in this study area is moderately high. We recommend the provision of health education programs for preventing and controlling diseases in schoolchildren, with the aim to reduce long-term morbidity and the socioeconomic impact.

Received 05/21/2018

Review began 06/20/2018

Review ended 07/13/2018

Published 07/18/2018

C) Copyright 2018

Chikoi et al. This is an open access article distributed under the terms of the Creative Commons Attribution License CC-BY 3.0., which permits unrestricted use, distribution, and reproduction in any medium, provided the original author and source are credited.
Categories: Pediatrics, Preventive Medicine, Infectious Disease

Keywords: skin fungal infection, prevalence, school-children

\section{Introduction}

Superficial skin fungal infections are fungal diseases that involve the skin, nails, mucous membrane, and hair [1]. The causative fungi have the ability to invade the superficial layers of the skin and the high keratin-concentration containing appendages, the hair and nails of the living host [2]. 
The condition is very common in schoolchildren and causes morbidity and lowers the quality of life of the affected children [3-4], posing a major public health problem causing, among others, poor attendance among school children in low- and middle-income countries like Tanzania. Factors such as poor personal hygiene, frequent human contact, poor environmental sanitation, overcrowding, and low socioeconomic status predispose school-age children to fungal infections [1,5-6].

Reports show that approximately $20 \%-25 \%$ of people worldwide are suffering from the diseases [7]. Studies from East and Southern parts of Africa shows that the prevalence of superficial skin fungal infections among schoolchildren in developing countries ranges between 20\% and 90\% [8]. In Tanzania, previous studies have documented prevalence rates of skin fungal infections among school-age children ranging from $12 \%$ to $55 \%$ [9-12]. The differences in prevalence are greatly attributed to differences in climatic and other geographical conditions in the studied areas.

The present study area also differs from previously studied regions in terms of climatic conditions; thus, it is imperative to assess the magnitude of skin fungal infections in this setting. This study was, therefore, designed to determine the current point-prevalence and associated risk factors of superficial skin fungal infections among primary school children in Southern Tanzania.

\section{Materials And Methods}

\section{Study design and setting}

This was a descriptive cross-sectional prospective study conducted in October 2017 in a public primary school in Songea municipal council.

\section{Sampling technique}

A list of all eight public and private primary schools was obtained from the municipal education authority. A multistage sampling technique was used that involved selection along primary schools, classes, and pupils from selected class strata. Only one school was selected from which a total of 500 out of 589 pupils from class 1 to class 7 were recruited regardless of their ages.

\section{Data collection and clinical assessment}

Selected children were interviewed and examined in daylight. All recruited pupils were interviewed to obtain their sociodemographic profiles. History to identify predisposing risk factors was also obtained. The socioeconomic status of their parents/guardians was determined using the modified wealth index [13]. The Canadian crowding index was used to determine the household living conditions of children [14]. To determine the presence of any superficial skin fungal infection, all participating pupils were examined thoroughly from head to toe with minimal clothing in a well-lit office within the school premises, and any observed fungal infection was then classified. To ensure privacy, the examinations were done in a separate private office in front of either one of their teachers of the same sex or the children's parents/guardians. The World Health Organization (WHO) hand and skin hygiene assessment tool was also used to assess the children's level of hygiene. A diagnosis of superficial skin fungal infection was mainly made clinically, and skin scrapings or nail clippings were taken to confirm the diagnosis. Pupils who had superficial skin fungal infections were treated accordingly by the examining doctors and preventive education about risk factors was provided to both the children and their parents/guardian.

\section{Ethical issues}




\section{Cureus}

Ethical clearance was obtained from the Institutional Research Ethics Committee, and permission to collect data was sought from the Municipal Executive Director, municipal education authority, and the school authority. The purposes and benefits of the study were explained to the pupils, parents/guardians, and teachers. Informed written consent from the parents/guardians of all pupils involved in the study was obtained. We excluded all pupils whose parents did not give consent and those who did not assent to participate.

\section{Statistical analysis}

Statistical analyses were done using Statistical Package for Social Sciences version 21 (SPSS Inc., Chicago, IL, USA). Continuous data were expressed as means \pm standard deviation (SD) and categorical data as percentages. The $\chi 2$ test and logistic regression analysis were used to determine associations for categorical variables. A p-value of less than 0.05 was considered statistically significant.

\section{Results}

\section{Socio-demographic characteristics and point prevalence of skin fungal infection}

A total of 500 out of the 589 pupils registered in the school were recruited for the study, with a response rate of $100 \%$. The age range was seven to 15 years and the mean age of all pupils was $9.92 \pm 1.13$ years. Males were 262 (52.40\%) and female pupils were 238 (47.60\%). The majority of children belonged to the age group of 10 to 12 years $(298,59.60 \%)$. Class 4 pupils formed the majority of the participants $(140,28.00 \%)$ while about $62.60 \%$ of the pupils' parents/guardian were married. Out of the 500 pupils, 176 pupils were found to have a superficial fungal infection giving a point-prevalence of $35.20 \%$. Females (59.09\%) were more affected than males (40.91\%), and this difference was statistically significant $(\boldsymbol{p}<\mathbf{0 . 0 5})$. The highest prevalence was found among the age group 10-12 years $(\boldsymbol{p}<\mathbf{0 . 0 5})$ and among pupils of classes 3 and $4(\boldsymbol{p}<0.05)$ (Table 1).

Variable

Sex

Male

Female

Age (years)

$7-9$

$128(25.60)$

$10-12$

$13-14$

$15+$ and above

Class

One \& Two

Three \& Four

$143(28.60)$

$163(32.60)$
Total number, $\mathbf{N}(\%)$

Status of Skin Fungal Infections

Present, $\boldsymbol{n}(\%) \quad$ Absent, $\boldsymbol{n}(\%)$
190 (58.64)

134 (41.36)

104 (59.09)

$49(27.84)$

$92(52.27)$

$34(19.32)$

$1(0.57)$

$44(25.00)$

99 (30.56)

$94(53.41)$
79 (24.38)

$206(63.58)$

0.03

36 (11.11)

$3(0.93)$ p-value

0.00 


\section{Cureus}

Five \& Six

Seven

Parents' marital status

Married

Single

Cohabiting

Polygamy

Divorced

Parents' occupations

Peasant

Employed

Businessmen/women

Others

Socio-economic status (SES)

Low SES

Middle SES

High SES

Unknown
146 (29.20)

$48(9.60)$

$313(62.60)$

$72(14.40)$

$24(4.80)$

$48(9.60)$

$43(8.60)$

$118(23.60)$

$190(38.00)$

$172(34.40)$

$20(4.00)$

$433(86.60)$

$39(7.80)$

$5(1.00)$

$23(4.60)$
28 (15.91)

10(5.68)

38 (11.72)

205 (63.27)

$25(14.21)$

47 (14.51)

$9(5.11)$

$15(4.63)$

0.71

$21(11.93)$

27 (8.33)

$13(7.39)$

$30(9.26)$

45 (13.89)

$51(28.98) \quad 139(42.90)$

0.00

$47(26.70) \quad 125(38.58)$

$5(2.84)$

$15(4.63)$

292 (90.12)

$16(4.94)$

0.00

$23(13.07)$

$4(1.24)$

$1(0.57)$

$12(3.70)$

TABLE 1: Socio-demographic characteristics of study subjects

\section{Clinical types of dermatophytosis lesions}

Of the 500 pupils who underwent the physical examination for skin fungal infections, 176 (35.20\%) were identified to have one or more types of suspected skin fungal infections lesions. Of these, Tinea capitis was the leading suspected skin fungal infection found in 86 children (48.86\%), followed by Tinea corporis, which was found in 35 pupils (19.89\%). Multiple infections of two types of dermatophytosis lesions were observed in 14/176 pupils (7.95\%)

(Figure 1). 


\section{Cureus}

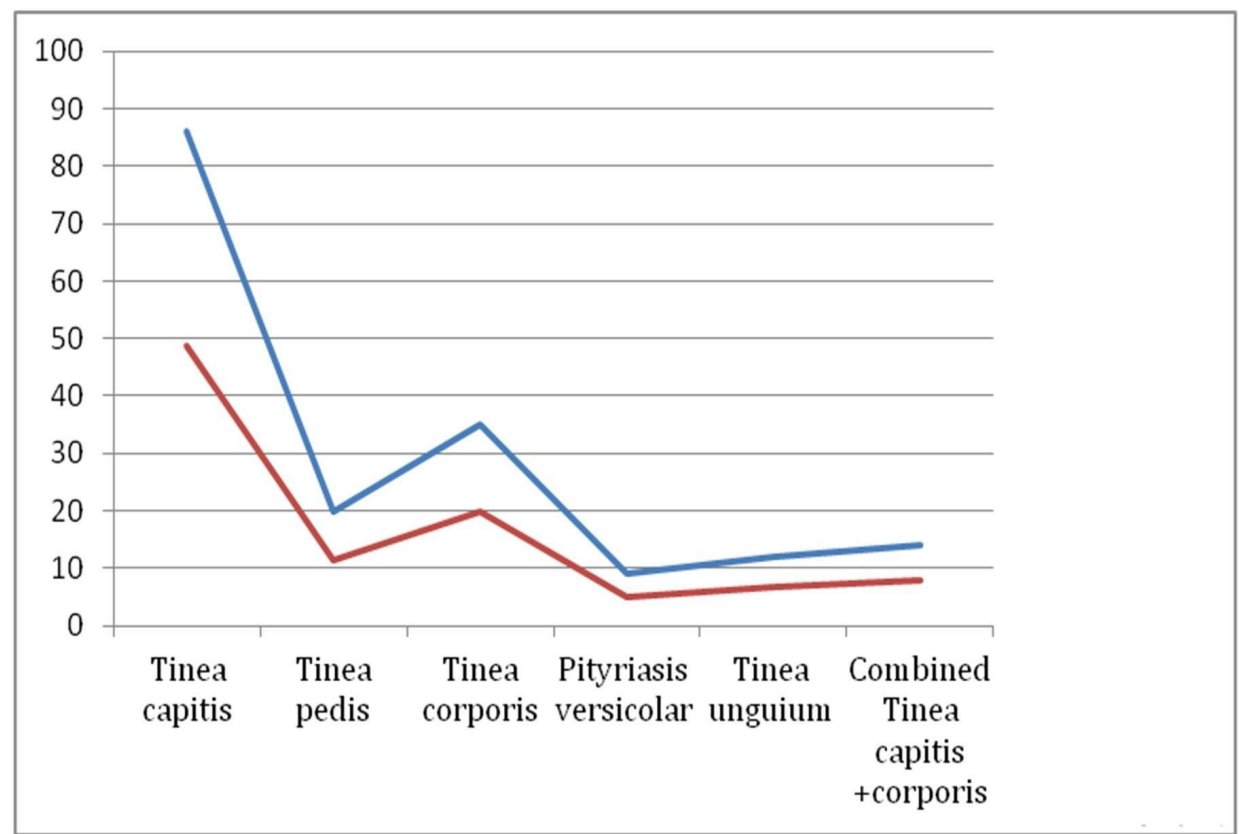

\section{FIGURE 1: Clinical types of skin fungal infection lesions}

among study participants

The red line represents the proportions of children with clinical types of dermatophytosis and the blue line shows the actual number of children with clinical types of dermatophytosis.

\section{Assessment of personal body hygiene}

We assessed the habits and behaviors of pupils regarding care of their skins. Of the 500 children interviewed, 376 (75.20\%) use safe tap-water for washing their clothes and bathing. About 440 (88\%) of the children wash their bodies only once a week. Furthermore, about $115(23 \%)$ pupils do not use soap when taking a bath. Almost 475 (95\%) pupils share combs and about 453 $(90.60 \%)$ share towels with their siblings or relatives (Table 2).

Risk factors

\section{Source of water}

Tap water

Well water

Other sources

Frequency of taking showers

Daily

Once a week

\section{Number, $\boldsymbol{N}$}

More than twice a week 


\section{Cureus}

Using soap during showers

Yes

Occasionally

Number of people per room

$1-3$

$4-10$

Number of people sharing a bed with the child

Comb sharing

Never

Yes

Towel sharing

Never 5

Yes

Occasionally

Sharing of clothes and shoes

Never

\section{TABLE 2: Personal hygiene and skin care-related habits among study subjects}

\section{Risk factors for skin fungal infections among study subjects}

We also performed a multivariate logistic regression analysis to determine the association between variables and the presence of fungal infection among children. The variables age between 10 and 12 years $(p<0.05)$ and between 13 and 14 years $(p<0.001)$, class of pupils $(p<0.05)$, having parents who are employed or dealing with business $(p<0.001)$, having parents of middle socioeconomic status $(\mathrm{p}<0.001)$, having a shower using water from other sources 


\section{Cureus}

$(\mathrm{p}<0.001)$, not taking a shower daily ( $\mathrm{p}<0.05)$, not using soap or using it occasionally when taking a shower $(p<0.001)$, staying or sleeping with more than three people in the same room $(\mathrm{p}<0.001)$, and sharing a bed with more than three people, were all significantly associated with the development of superficial skin fungal infections (Table 3).

\section{Predictor variables}

Age (years)

$7-9$

$10-12$

$13-14$

$15+$ and above

Class

One \& Two

Three \& Four

Five \& Six

Seven

Parents' marital status

Married

108

Single

Cohabiting

Polygamy

Divorced

Parents' occupations

Peasant

73

Employed

Businessmen/women

Others

Socio-economic status (SES)

Low SES

Middle SES

141

23

1

49

92

34

1

44

94

28

10

25

9

21

13

51

47

5

High SES

Status of skin fungal infection

Present, $n \quad$ Absent, $n \quad$ OR $(95 \% \mathrm{Cl})$

p-value

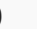

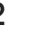

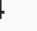

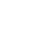

4

4

118

118

38

79

1.00

206

$0.63(043-0.91)$

0.02

36

$2.12(1.27-3.52)$

0.00

3

$0.61(0.06-5.92)$

1.00

1.00

$4.24(2.85-6.31)$

0.00

$0.33(0.21-0.52)$

0.00

$0.45(0.22-0.93)$

0.04

5

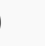

15

27

30

205

1.00

47

$0.98(0.58-1.65)$

1.00

$1.11(0.48-2.59)$

$1.49(0.82-2.72)$

0.21

$0.78(0.40-1.54)$

0.51

139

125

15

0.00

$0.60(0.22-1.69)$

0.36 


\section{Cureus}

Unknown

Source of water

Tap water

Well water

Other sources

Frequency of taking showers

Daily

More than twice a week

Once a week

Using soap during showers

Yes

Never

Number of people per room

$1-3$

$4-10$

$>10$

Number of people sharing a bed with the child

Sleeping alone

$>3$

Comb sharing

Never

Yes

Occasionally

Towel sharing

Never

Yes

Occasionally

Sharing of clothes and shoes

Never
28

47

101

12

96

68

100

51

25

1

11

164

276

$0.44(0.22-0.87)$

0.02

$2.38(1.23-4.61)$ 0.00

108

49

19

309

12

306

1.00

4

$29.15(10.29-82.56)$

0.00

14

$29.82(16.15-55.06)$

0.00

116

204

4

1

170

5

1

156

19

11

28

1.00 


\section{Cureus}

Yes

Occasionally

\section{TABLE 3: The logistic regression analysis of the risk factors for acquiring superficial skin fungal infections among pupils $(n=500)$}

Abbreviations: $\mathrm{n}$, positive number; $\mathrm{OR}$, odds ratio; $\mathrm{Cl}$, confidence interval

\section{Discussion}

This community-based cross-sectional study described the magnitude and risk factors of skin fungal infections among primary schoolchildren at a public school in Southern Tanzania. The study recruited 500 pupils with an almost equal male: female enrollment (1:1.1). The pupils' mean age was $9.92 \pm 1.13$ years with the majority of the pupils belonged to the age group 10-12 years. The studied age group is the most affected population worldwide, and this profile is in line with those reported elsewhere [10-12,15] and is within the reference school-age range of six to 12 years. Significantly more girls were found to have skin fungal infections than boys. This is a surprising finding because boys are more hyperactive than girls, thus one would expect them to be more infected than girls. The possible explanation for this contra-observation could be related to the culture of the local people who involve young girls in participating in household work, which could likely predispose them to skin infections. We also observed that the infections affected more children from families with a low social economic status and peasants parents. This observation is in line with suggestions that superficial skin fungal infections are diseases of poverty and tend to run through poor communities.

The present study found a point-prevalence of superficial skin fungal infections of $35.20 \%$. This prevalence lies between those previously reported by other studies done in the country [9-12] and elsewhere [5-7]. This moderately high prevalence reflects unhygienic environmental health conditions that favor the occurrence of skin fungal infections in this study population. This finding is also an indication of the poor socioeconomic status prevailing in the study area. Kalu et al. [15], Oyedeji et al. [16], and Saheed et al. [17] all reported similar environmental conditions in their study areas, which included the low socioeconomic status of communities, poor personal hygiene practices among children, low level of education, inadequate environmental health practices, poor water distribution, and adverse socio-cultural practices. As skin fungal infections are a disease of poverty, much needs to be addressed by the respective communities to curb the problem.

Five clinical types of suspected fungal infections were identified by clinical examination. Tinea capitis was the most prevalent suspected skin fungal infection observed in $49 \%$ of the pupils followed by Tinea corporis observed in $20 \%$ of the pupils. About $8 \%$ of pupils had multiple clinical types of dermatophytosis lesions. Our findings are contrary to those reported by Jena in India who reported that where pityriasis versicolor affected more than $30 \%$ of the children between infancy and age 14 years [18], while Guan-Yu Chen et al. in Taiwan reported contrary findings, where Tinea nigra and Tinea versicolor accounted for $0.09 \%$ of the clinical dermatophytosis, respectively [19]. The differences could be attributed to the geographical and climatic differences between the study areas in which the present study area has mostly longrainy seasons and cold weather contrary to India and Taiwan, which have hot seashores and dry environments that facilitate sweating and the attachment of the organism to the skin surface. The head and body being relatively exposed parts are likely the most commonly afflicted areas 
by Tinea capitis and Tinea corporis in this setting, probably due to such factors as overcrowding of children in classes, frequent body contact with their friends, and poor personal body hygiene. Being mostly asymptomatic and harmless, the condition may be ignored by the pupils and their parents and, hence, can easily be further transmitted to other pupils.

We identified various factors as being significant for the occurrence of skin fungal infections in this study population. They included sociodemographic characteristics, such as age of pupils of less than 14 years, class, parents being employed or businessmen/women, and parents being in the middle economic status. Behavioral factors, such as using other sources of water for bathing and washing clothes, not taking shower daily, not using soap during showers, staying or sleeping in overcrowded rooms, and sharing a bed with more than three people. Our findings are similar to those reported elsewhere $[5-7,11,15]$.

Contrary to our findings, Figueroa et al. in their study in South Western Ethiopia found overcrowding not to be significantly associated with infection [6]. Similar findings were also reported by Olutoyin et al. in South Western Nigeria who observed an increased prevalence of skin fungal infections in the urban community than in the rural community and that more people who live in crowded conditions had skin fungal infections than those living in less populated homes although this relationship was not statistically significant [20]. Our findings are in line with the well-known fact that skin fungal infections, being transmitted mainly through skin-to-skin contact, tend to be prevalent in areas where there are overcrowding and possible frequent skin contacts between children.

Children whose parents were employed or were dealing with business had a significantly higher burden of the disease than their counterparts. Because of their parents' occupation, it is probable that these children lacked proper and close supervision of their health and effective care, such as good personal hygiene, taking regular showers, and even better personal grooming than their age group. However, our findings are contrary to those reported by Olutoyin who reported low incidences of skin infections among children who stay with parents of similar status [20]. Nevertheless, proper and close supervision of children's behaviors and habits leading to personal body hygiene are key to the prevention of skin fungal infections.

Parents' socioeconomic status has been one of the main factors associated with the development of superficial fungal infections among pupils. Previous studies have shown that children with parents of low socioeconomic status were reported to have an increased prevalence of superficial fungal infections [6-7,10-12,17,20]. On the contrary, our study showed that a middle socioeconomic status was significantly associated with the increasing prevalence of skin fungal infections than a low socioeconomic status. Despite this finding, poverty is one of the main reasons perpetuating the existence of skin fungal infections in this study environment. Pupils from families with a high or middle socioeconomic status are likely to observe and practice hygienic principles than are pupils from poor families.

Sharing of clothes, combs, towels, or shoes have been reported elsewhere to be good sources of the transmission of superficial fungal infection [6-7,10-12,20]. In this present study, although Tinea capitis and Tinea corporis were the most observed prevalent clinical types, there was no significant association between the sharing of the items with the development of skin fungal infections. Most of the pupils are from poor families with the majority taking a bath only once a week. The sharing of such items, which are very likely to be dirty and unhygienic, poses the risk of contracting skin fungal infections among pupils.

Such factors as personal hygiene among pupils influence the transmission of superficial fungal skin infection as reported in this study and elsewhere. Our findings suggest that to prevent and control the spread of skin fungal infection, measures to improve personal hygiene among 
pupils should be encouraged. Strategies such as health education to both pupils and their parents/guardians can help increase awareness of the disease and change personal health behaviors among children.

Our study used only one public school with the majority of the pupils from the same area and who had more or less similar health environments, cultures, and taboos. The results, therefore, cannot be generalized to other private schools, which have children mostly from families with good or middle socioeconomic status and different cultures and health environments.

\section{Conclusions}

Our findings indicate that the magnitude of superficial skin fungal infections among schoolgoing children is moderately high and that socio-demographic and behavioral factors profoundly influence the development and occurrence of these infections in children in this study area. Heath education programs are necessary for preventing and controlling the diseases in schoolchildren, with the aim to reduce long-term morbidity and the socioeconomic impact.

\section{Additional Information}

\section{Disclosures}

Human subjects: Consent was obtained by all participants in this study. Research Ethics Committee of Archbishop James University College issued approval N/A. Animal subjects: All authors have confirmed that this study did not involve animal subjects or tissue. Conflicts of interest: In compliance with the ICMJE uniform disclosure form, all authors declare the following: Payment/services info: All authors have declared that no financial support was received from any organization for the submitted work. Financial relationships: All authors have declared that they have no financial relationships at present or within the previous three years with any organizations that might have an interest in the submitted work. Other relationships: All authors have declared that there are no other relationships or activities that could appear to have influenced the submitted work.

\section{References}

1. Kelly BP: Superficial fungal infections. Pediatr Rev. 2012, 33:e22-37. Accessed: June 17, 2018 : 10.1542/pir.33-4-e22

2. Weitzman I, Summerbell RC: The dermatophytes. Clin Microbiol Rev. 1995, 8:240-259. Accessed: Jan 8, 2018: https://www.ncbi.nlm.nih.gov/pmc/articles/PMC172857/.

3. Mohammedamin RS, van der Wouden JC, Koning S, van der Linden MW, Schellevis FG, van Suijlekom-Smit LWA, Koes BW: Increasing incidence of skin disorders in children? A comparison between 1987 and 2001. BMC Dermatol. 2006, 6:4. Accessed: December 27, 2017: 10.1186/1471-5945-6-4

4. Walker N, Lewis-Jones MS: Quality of life and acne in Scottish adolescent schoolchildren: use of the Children's Dermatology Life Quality Index (CDLOI) and the Cardiff Acne Disability Index (CADI). J Eur Acad Dermatol Venereol. 2006, 20:45-50. Accessed: February 2, 2018: 10.1111/j.1468-3083.2005.01344.X

5. Inanir I, Sahin MT, Gunduz K, Dinc G, Turel A, Ozturkcan S: Prevalence of skin conditions in primary school children in Turkey: differences based on socioeconomic factors. Pediatric Dermatol. 2002, 19:307-311. Accessed: June 17, 2018: https://onlinelibrary.wiley.com/doi/abs/10.1046/j.1525-1470.2002.00087.x.

6. Fiqueroa JI, Fuller LC, Abraha A, Hay RJ: The prevalence of skin disease among school children in rural Ethiopia - a preliminary assessment of dermatologic needs. Pediatric Dermatol. 1996, 13:378-381. Accessed: June 13, 2018: 10.1111/j.1525-1470.1996.tb00704.x

7. Havlickova B, Czaika VA, Friedrich M: Epidemiological trends in skin mycoses worldwide. Mycoses. 2008, 51:2-15. Accessed: June 12, 2018: 10.1111/j.1439-0507.2008.01606.x

8. Nweze EI, Eke IE: Dermatophytes and dermatophytosis in the eastern and southern parts of 
Africa. Med Mycol. 2018, 56:13-28. Accessed: June 16, 2018: 10.1093/mmy/myx025

9. Komba EV, Mgonda Y: The spectrum of dermatological disorders among primary school children in Dar es Salaam. BMC Public Health. 2010, 10:765. Accessed: November 25, 2017: 10.1186/1471-2458-10-765

10. Ferie J, Dinkela A, Mbata M, Idindili B, Schmid-Grendelmeier P, Hatz C: Skin disorders among school children in rural Tanzania and an assessment of therapeutic needs. Trop Doct. 2006, 36:219-221. Accessed: March 3, 2018: 10.1258/004947506778604823

11. Satimia FT, McBridge SR, Leppard B: Prevalence of skin diseases in rural Tanzania and factors influencing the choice of health care, modern or traditional. Arch Dermatol. 1998, 134:13631366. Accessed: December 4, 2017: 10.1001/archderm.134.11.1363

12. Gibbs S: Skin disease and socioeconomic conditions in rural Africa: Tanzania . Int J Dermatol. 1996, 35:633-639. Accessed: January 15, 2018: 10.1111/j.1365-4362.1996.tb03687.x

13. Rutstein Shea O, Kiersten J: The DHS Wealth Index. DHS Comparative Reports. 2004, 6:1-77. Accessed: April 7, 2018: https://dhsprogram.com/publications/publication-cr6-comparativereports.cfm.

14. Household crowding - Social Report 2010 . (2010). Accessed: January 23, 2018: http://socialreport.msd.govt.nz/2010/economic-standard-living/household-crowding.html.

15. Kalu EI, Wagbatsoma V, Ogbaini-Emovon E, Nwadike VU, Ojide CK: Age and sex prevalence of infectious dermatoses among primary school children in a rural South-Eastern Nigerian community. Pan Afr Med J. 2015, 20:182. 10.11604/pamj.2015.20.182.6069

16. Oyedeji OA, Oyedeji GA, Oyelami OA, Onayemi O: A comparative survey of the prevalence and pattern of skin infections and infestations between urban and rural Nigerian primary school pupils. Int J Trop Med. 2007, 2:126-130. Accessed: December 12, 2017: http://medwelljournals.com/abstract/?doi=ijtmed.2007.126.130.

17. Saheed AB: Poverty situation in Nigeria: an overview of rural development institutions . PJSS. 2010, 7:351-356. Accessed: January 13, 2018: 10.3923/pjssci.2010.351.356

18. Jena DK, Sengupta S, Dwari BC, Ram MK: Pityriasis versicolor in the pediatric age group . Indian J Dermatol Venereol Leprol. 2005, 71:259-261. Accessed: Jan 27, 2018: 10.4103/03786323.16618

19. Chen GY, Cheng YW, Wang CY, Hsu TJ, Hsu MML, Yang PT, Chen WC: Prevalence of skin diseases among school children in Magong, Penghu, Taiwan: a community-based clinical survey. J Formos Med Assoc. 2008, 107:21-29. Accessed: December 19, 2017: 10.1016/S09296646(08)60004-2

20. Olutoyin OO, Onayemi O, Gabriel AO: Risk factors associated with acquiring superficial fungal infections in school children in South Western Nigeria: a comparative study. Afri Health Sci. 2017, 17:330-336. Accessed: Jan 9, 2018: 10.4314/ahs.v17i2.6 